\title{
Unos Versos Olvidados de José María Heredia
}

Dos cuestiones sin resolución en la biografía literaria del poeta cubano José María Heredia son su presunta precocidad y la intensidad de su celo revolucionario. La imagen tradicional es, a no dudarlo, la de un vate inspirado muy joven por el patriotismo y motivado a escribir poesías notables y a comportarse en efecto con tanta osadía que por fin se vio proscripto, bajo sentencia de muerte. Su primera permanencia en México, 1819-1821, cuando dice la opinión común que se inició en la lírica patriótica, no se conoce sino mal. Por tanto es de interés especial el recobrar unos versos suyos escritos en 1820 y perdidos de vista tan completamente que no se volvieron a publicar ni figuran en ninguna bibliografía de las obras de Heredia.

En la hermosa colección de panfletos mexicanos del siglo xIx pertenecientes a la Sutro Library de San Francisco, California, hay uno que contiene el siguiente poema, sobre el pie de imprenta "Méjico: 1820/ Imprenta de Don Alejandro Valdés":

\section{HIMNO PATRIOTICO}

Que se cantó en el Teatro de Méjico

LA NOCHE DEL 21 DEL CORRIENTE EN

CELEBRIDAD DE LA INSTALACIÓN DE LA

Excma. Diputación Provincial.

COMPUESTO POR

Don José Maria Heredia 


\section{CORO}

Levantad, españoles, la frente, levantadla del polvo en buen bora, que ya luce de gloria la aurora tras la nocbe de luto y borror.

Volved dó quier la vista, volvedla, ciudadanos, y las gozosas manos al cielo levantad.

Ya la desdicha nuestra en gozo se ha tornado, pues hemos aclamado la santa libertad.

\section{CORO}

Sí, que el rey más amable, FERNANDo generoso, del yugo ingnominioso librara al español.

Su nombre, ciudadanos, al cielo levantemos, y grande le aclamemos con fervoroso amor.

\section{CORO}

Viva, decid mil veces

FERNANDo el adorado, que el código sagrado de libertad juró.

El código que inflama en noble ardor al bueno, $y$ al que de espanto lleno ve el déspota feroz. 


\section{CORO}

Ya Iberia no recela* que un déspota insolente con ánimo inclemente la venga á destrozar.

$\mathrm{Ni}$ ya teme cual antes

el quieto ciudadano que poderosa mano

le pueda atormentar.

\section{CORO}

Si un pérfido algún día altivo se levanta, y con soberbia planta nos pretendiere hollar,

Entonces el. congreso de Iberia soberano, hará su intento vano, clamando jlibertad!

\section{CORO}

Ya veis en nuestro suelo

Ia Junta que zelosa sobre la ley hermosa constante velará.

Ya un freno en ella tiene*

la negra tiranía: cantares de alegría se escuchen resonar.

* Esta estrofa y la siguiente no se cantaron. [Nota de Heredia].

* Este verso y el siguiente se omitieron. [Nota de Heredia]. 


\section{CORO}

Ya veis del libro santo los frutros [sic] producidos: vivir libres y unidos, ¿habrá dicha mayor?

Huya la atroz discordia, desármense los brazos, y estréchense los lazos del indio, y español.

\section{CORO}

\section{Los odios y rencores}

por siempre abominemos, $y$ ledos afirmemos eterna y dulce unión.

Viva Fernando ilustre reinando felizmente $y$ viva eternamente la ley de la Nación.

\section{Levantad, españoles, la frente, levantadla del polvo en buen bord, que ya luce de gloria la aurora tras la noche de luto y horror.}

He aquí los acentos juveniles articulados por un estudiante universitario de dieciséis abriles, arrastrado por el oleaje de regocijo casi frenético que arrolló a los liberales mexicanos, cuando estos americanos se unían a los peninsulares para festejar el restablecimiento de la constitución de 1812, acatada a la fuerza por Fernando VII en marzo de 1820. Imposible sería exagerar la "fiebre constitucional" que agitó a cada progresista y le acicateó, si tenía las pretensiones literarias más leves, para que compusiera su panegírico, canto triunfal o himno. Al mismo tiempo, empero, los serviles, enfriados por la mengua de sus privilegios y 
por el supuesto peligro de anarquía, se ingeniaron por aguarles la fiesta a los constitucionales.

Puede fijarse la fecha de este poema con mucha certeza: julio de $1820 ; 1$ lo que determina esta composición como uno de los escritos libertarios más tempranos de Heredia. El primero cuya fecha queda firmemente establecida es una octava real publicada en el Diario del Gobierno Constitucional de la Habana del 25 de abril de 1820.2 No obstante lo pedestre de su versificación y lo trillado de su alabanza de los patriotas españoles, esta octava sí señala dos circunstancias interesantes: primera, que Heredia estuvo en la vanguardia de los liberales mexicanos; y segunda, que su ardor llegó hasta tal punto que quiso burlar la hostilidad del virrey Apodaca y su séquito publicando los versos fuera de México. Este hecho corrobora la reclamación formulada por el anónimo "F. F." de un panfleto fechado el 7 de junio de 1820, la Carta de un constitucional de Méjico á otro de la Habana (México: reimpresa en la oficina de D. Alejandro Valdés, 1820): ${ }^{3}$

En fines de abril no se ignoraban en Méjico los principales acontecimientos de España, pero el hablar de ellos era punto ménos que provocar la pezquiza [sic] inquisitorial. Los papeles públicos, hasta las gacetas de Madrid, han permanecido ocultos en todo el mes de mayo, sin que se haya permitido á las prensas su publicación. Aun hay más. Se juró la Constitución el 31 del que ha finado, iy cree $V$. que está en práctica el artículo 371 del Código sagrado? Nada menos que eso. No se ha permitido la reimpresión de la sábia y enérgica esposición de la

1 Existían o estaban en formación durante 1820, dos "Diputaciones Provinciales": (1) la interina instalada por orden del virrey Apodaca el 20 de julio, con los mismos individuos que en 1816 , año de su supresión a la vuelta de Fernando VII; y (2) otra permanente a cuya elección se dio comienzo, de conformidad con el decreto real, el 18 de septiembre. Heredia ha de referirse a la primera, pues a pesar de no hallarse otra alusión a la ceremonia mencionada por el poeta en su título, la única instalación de esta índole descrita en los periódicos oficiales o semioficiales de la época es la de la diputación provisional (véase Gaceta del Gobierno de México, núm. 94, 20 de julio, 1820; y Noticioso General, núm. 714, 26 de julio, 1820). Además, la noche del viernes 21 de julio sería oportuna para una aclamación popular, como lo fue el acto celebrado en el Coliseo, porque sigue la acción del virrey y precede las solemnidades oficiales en la catedral el día sábado 22. Sólo entonces hizo la Diputación sus primeros trámites.

2 Francisco González del Valle, Cronologia berediana (La Habana, 1938), p. 93 .

3 En la Bancroft Library, Berkeley. California, 
junta de Zaragoza. La noche del 5 debió represertarse en el teatro la comedia anunciada por impresos titulada: Ver derrocado en Galicia, el orgullo y la injusticia. Este título caracterizado por constitucional pusó [sic] en alarma á nuestro gefe, que inmediatamente prohibió su ejecución. Esto quiere decir que se ha jurado la teoría de la constitución con ánimo de infringirla [p. 5].

Hasta el 30 de mayo tardó en llegar a México la noticia oficial del restablecimiento, jurando el virrey sin ganas al día siguiente.

Entretanto sugiere una cristalización de ideología política en Heredia una carta que, bajo fecha del 3 de mayo, dirige a su padre; situación bastante curiosa, pues ambos vivian en la capital-en la misma casa, con toda probabilidad-y no hay por qué suponer que el padre la viese jamás. Aquí confiesa el joven que aún antes de restablecerse la constitución, "acaso desfogué mi odio hacia la esclavitud con algunas composiciones que por falta de corrección, y más bien por mi poco empeño en concluirlas (viendo el ningún efecto que suelen producir las quejas dolorosas de los oprimidos), no han llegado a noticia de Ud."4 Al terminar, ruega a su padre que oiga los sentimientos cívicos que manan de su corazón. Es lícito conjeturar que es ésta una referencia a la oda España libre, publicada en México a fines de la primavera o durante el verano de 1820 , reimpresa alli una vez, por lo menos, en el mismo año y también en La Habana el 16 de agosto. Es probable que no se editase sino después del 31 de mayo. 5

Quedan, pues, dos "Himnos patrióticos" como saldo de los poemas libertarios compuestos por Heredia en México. De éstos uno es el conocido Himno patriótico al restablecimiento de la Constitución, también con

4 Heredia, Prédicas de liberiad (La Habana, 1936), p. 41.

5 Es notable el enlace ideológico entre la carta y la oda, si se comparan ciertas frases en ambas. Al dedicar el poema a Emilio Rodríguez, escribe Heredia, " PPodamos un día ofrecer á la Pátria servicios reales en lugar de empalagosos y estériles himnos!" En la carta pone "¡Ojalá algún día, llevado de mis patrióticos sentimientos y de los sabios consejos de Ud., pueda tributarle como testimonio de mi sincera gratitud, en lugar de empalagosos y estériles himnos, los honrosos y sagrados setvicios de ciudadano!" (énfasis añadido). Me parece difícil que nadie, ni siquiera un adolescente inexperto, fuese tan indiscreto que presentase la misma fórmula a dos hombres distintos, al lisonjearlos. Creerlo sería, a lo menos, dudar la espontaneidad de la modestia herediana. Me inclino por eso con más convicción a aceptar la hipótesis que la carta dejó de llegar a manos de don José Francisco. limitándose a sẹr una página más en el cuaderno de un esçtitor aprendiz. 
estribillo coral, pero que en las estrofas principales utiliza las octavas italianas, decasilabas, que a principios del siglo xIx eran "populares en cantos patrióticos ... entonados por la multitud".6 Da gracias a Fernando VII y alaba a los héroes del 20, sobre todo a Antonio Quiroga. Es, sin duda, posterior a España libre, porque no aparece en las Obras poéticas, manuscritas y arregladas por Heredia en 1820, y España libre, en cambio, es el último poema de la colección.

El alboroto de aquellos tiempos puede explicar en gran parte que la verdadera paternidad literaria del Himno patriótico... que se cantó escapase la vigilancia del gran bibliógrafo José Toribio Medina. En La imprenta en México (1539-1821), cataloga como el número 11909 del tomo VIII un título que es idéntico a nuestro Himno, con la sola excepción de que falta el nombre de Heredia. Medina registró el panfleto del cual forma parte este poema, bajo el nombre de Manuel María Jiménez, autor de "otro himno al mismo tema", que integra la segunda sección de esta publicación constante de ocho páginas. Es claro que se trata del mismo panfleto, con la excepción ya notada, que posee la Sutro Library, el que contiene el mismo número de páginas, las ties últimas ocupadas por un poema de este título: HIMNO PATRIOTICO/ COMPUESTO/ POR DON MANUEL MARIA JIMENEZ,/ PARA QUE SE CANTASE EN ESTE COLISEO/ EN LA FUNCION DE LA EXCMA. JUNTA/ PROVINCIAL, LO QUE NO SE VERIFICO POR/ NO HABERLo PERMITIDO EL CENSOR. Como el himno de Heredia, es una octavilla italiana, con estribillo coral, pero hexasilabo. Está igualmente recargado de grandilocuencias pero respira más fuego y niega todo encomio al rey Fernando, a la vez que amenaza con más rigor rechazar cualquier intento de despotismo en el futuro.

El enigma del Himno... que se cantó puede esclarecerse un tanto con una reconstrucción de sus circunstancias. Se deben tomar en cuenta estas condiciones: primera, que la censura era entonces una cuestión batallona, y menudeaban las denuncias a raíz de toda declaración pública; segunda, que era paradójicamente posible imprimir algunas cosas cuya declaración oral quedaba en entredicho; tercera, que se celebraban frecuentes reuniones populares en el Teatro de México, conocido también por el Coliseo, y estos mítines eran entretenidos por cantos cuya letra se componía para la ocasión. Ilustran todas estas condiciones no solamente las dos poesías del panfleto, donde se advierte la mano del censor, sino

6 E. C. Hills, en Hills y Morley, Modern Spanish Lyrits (N. Y., 1913), p. 1xxiii, 
también otros dos poemas parecidos que he hallado. Uno es la anónima "Canción patriótica" del Semanario político, uno de los muchos periódicos efímeros de aquellos tiempos, y va en el número del 19 de julio de 1820. Hay un prólogo: "Se compuso para cantarse en el teatro la noche del 15 del corriente; pero no habiéndose querido sujetar su autor á hacerla ciertas correcciones que se le exigieron, por parecer demasiado fuertes varias espresiones, prefirió el partido de insertarla en el semanario para que el público la juzgue". Aquí tenemos a continuación las convencionales octavas decasílabas, cuyo tono se fija desde los primeros versos: "Levantad, ciudadanos, el grito,/ fuerte grito que atruene al malvado". El otro poema aparece sin título en el Noticioso general del 29 de septiembre de 1820, y ostenta un encabezamiento del mismo tipo: "Sr. Editor: - Sirvase vd. insertar en su Noticioso la siguiente canción patriótica, compuesta por mi para que se cantase en este teatro la noche del 19 del corriente; no pudo ser, porque no quise sujetarme á las supresiones y correcciones ridículas que quiso achacarle el censor. - Un constitucional". Los versos obedecen a la misma forma que el Himno patriótico al restablecimiento de la Constitución. Empieza así: "Diputados, marchad en buen hora/ Hácia el templo de Temis sagrada", con respecto a los diputados elegidos para representar a México en las Cortes españolas, a distinción de la Diputación Provincial.

De este modo el joven Heredia y su acompañador Jiménez, al dar con la censura, no andaban solos sino que pueden considerarse como pioneros en el movimiento de desobediencia civil en la cuestión constitucional. Con facilidad nos podemos figurar el efecto de este panfleto en el ambiente estrecho, inquieto y chismoso de la capital mexicana. Para los serviles la diferencia entre la culpa de Heredia y la de Jiménez sería pequeñísima. Tampoco, para valorar bien el hecho, hay que olvidar al padre de Heredia. A pesar de ser, como lo atestiguan las palabras cariñosas del hijo, defensor de causas justas, era sin embargo oficial del gobierno ibero, portador del título "Sr. Alcalde de Corte y Juez de Provincia" (Not. Gen., 9 de junio, 1820). Evidentemente el desafío lanzado por su hijo al censor habría de causarle a don José Francisco alguna incomodidad, en el mejor de los casos, aunque el padre no mostrase tanta rectitud en el cumplimiento de su deber, que era precisamente el mantenimiento de las leyes, por muy ingratas que fuesen. No es verosímil que dejara a su hijo desmandarse con ninguna autoridad legal; por esta razón entre otras posibles, sin duda, José María había optado por ocultar sus tempranos poemas cívicos. 
¿Sacaron del Himno patriótico el nombre de Heredia? ¿Demostró éste demasiada docilidad al permitir la mutilación de su primer texto, cuando otros, en circunstancias parecidas, se negaron a transigit? Cualesquiera que sean las respuestas, se trata de las capacidad de un adolescente para resistir la autoridad de sus mayores. En todo caso, la recuperación de estos versos da un poco más de relieve a la precocidad política de Heredia, si bien no aumenta su precocidad poética.

University of California,

ARNold Chapman

Berkeley. 
